Supplement of Atmos. Chem. Phys. Discuss., 15, 17843-17886, 2015

http://www.atmos-chem-phys-discuss.net/15/17843/2015/

doi:10.5194/acpd-15-17843-2015-supplement

(C) Author(s) 2015. CC Attribution 3.0 License.

(c) (i)

Supplement of

\title{
Observation of isoprene hydroxynitrates in the Southeastern United States and implications for the fate of $\mathbf{N O}_{x}$
}

\section{F. Xiong et al.}

Correspondence to: P. B. Shepson (pshepson@purdue.edu)

The copyright of individual parts of the supplement might differ from the CC-BY 3.0 licence. 


\section{CIMS calibration results for 4,3-IN}

Multiple CIMS calibrations for 4,3-IN have been conducted overtime, and the results were stable (Figure S1).

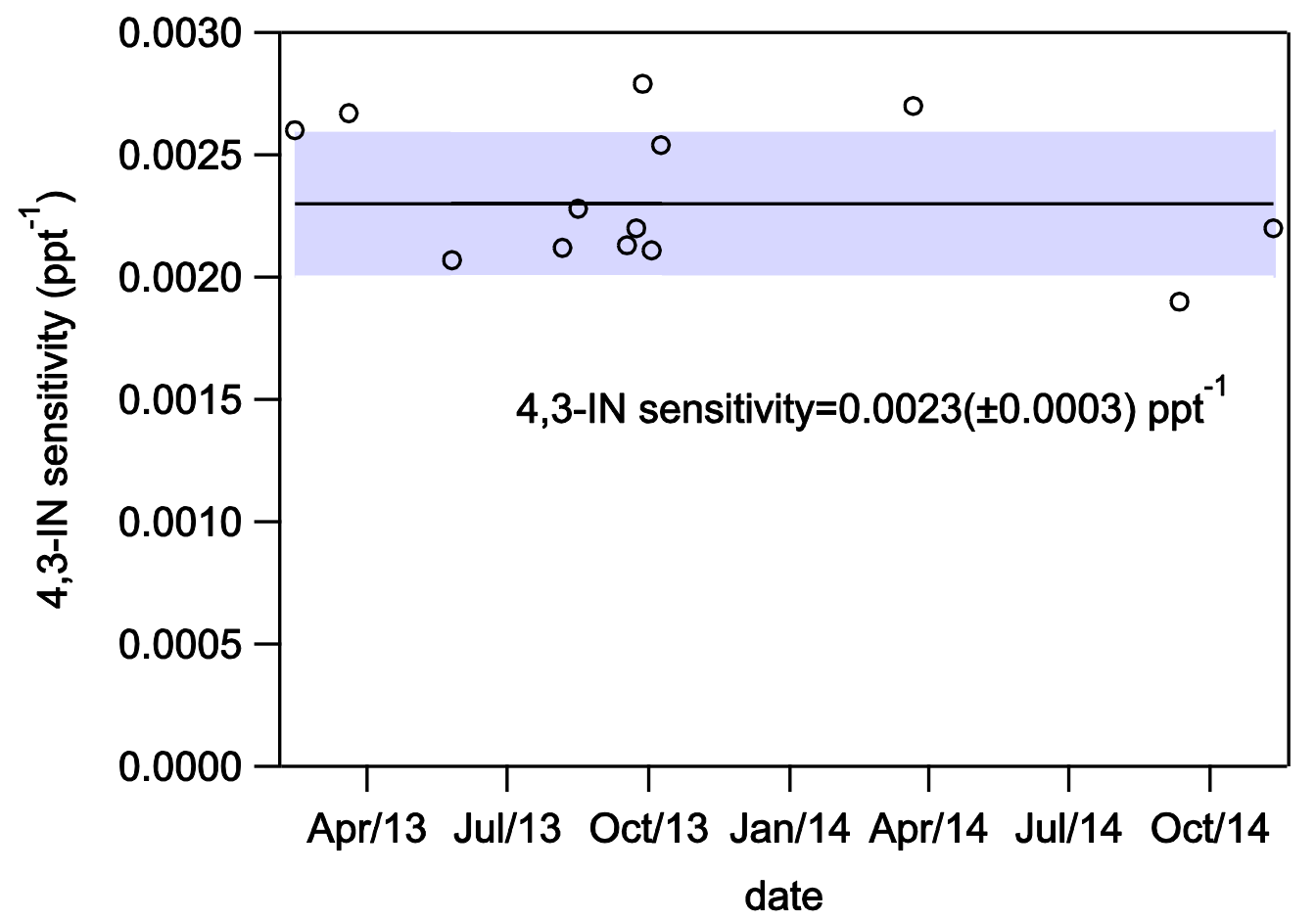

Figure S1. Calibration results for 4,3-IN. Each data point represents one calibration curve. The blue shade shows $1 \sigma$ standard deviation of the measured sensitivity. 


\section{CIMS sensitivities for cis- and trans-1,4-IN}

Three CIMS calibrations were conducted using standard solutions that contained a mixture of cisand trans-1,4-IN. The relative abundance of the cis and trans isomers was determined from NMR spectra. The overall sensitivity and relative isomer abundance are listed in Table S1.

Table S1. Overall sensitivity and isomer composition for cis- and trans-1,4-IN calibration.

\begin{tabular}{ccc}
\hline Calibration & Sensitivity $\left(\mathrm{ppt}^{-1}\right)$ & Isomer composition (trans relative to cis $)$ \\
\hline 1 & $5.0( \pm 0.5) \times 10^{-4}$ & $3.4 \pm 0.2$ \\
2 & $5.0( \pm 0.8) \times 10^{-4}$ & $4.1 \pm 0.3$ \\
3 & $5.6( \pm 0.8) \times 10^{-4}$ & $3.4 \pm 0.2$ \\
\hline
\end{tabular}

If we assume $x$ is the sensitivity for trans-1,4-IN and $y$ is the sensitivity for cis-1,4-IN, the isomerweighted sensitivity measured by CIMS can be written as following.

$0.77 x+0.23 y=5.0 \times 10^{-4}$

$0.80 x+0.20 y=5.0 \times 10^{-4}$

$0.77 x+0.23 y=5.6 \times 10^{-4}$

Due to the uncertainties in the coefficients in equation (1) to (3), $x$ and $y$ in the above equation system cannot be solved. Therefore, we define function $z$ through the following expression.

$z=\left[5.0 \times 10^{-4}-(0.77 x+0.23 y)\right]^{2}+\left[5.0 \times 10^{-4}-(0.80 x+0.20 y)\right]^{2}+\left[5.6 \times 10^{-4}-(0.77 x+0.23 y)\right]^{2}$

The true values of $x$ and $y$ can be approximated by finding the minimum of $z$. Using this method, we calculate the sensitivity for trans-1,4-IN to be $3( \pm 2) \times 10^{-4} \mathrm{ppt}^{-1}$ and the sensitivity for cis-1,4IN to be $1.3( \pm 0.3) \times 10^{-3} \mathrm{ppt}^{-1}$. 


\section{IN isomer distribution in chamber and field studies}

\subsection{Model simulation for chamber studies}

An iterative method was used to determine the IN isomer distribution in chamber studies. The relative yield of the eight isoprene $\mathrm{RO}_{2}$ radicals was used as the initial guess. The $\mathrm{RO}_{2}$ isomeric distribution was calculated with the Kintecus simulation software (website http://www.kintecus.com/), based on the $\mathrm{RO}_{2}$ interconversion and $\mathrm{H}$-shift reaction rate constants proposed in the LIM1 mechanism (Peeters et al., 2014). An isomer-weighted IN sensitivity was derived from the calculated $\mathrm{RO}_{2}$ isomer distribution. This sensitivity was used to calculate the initial guess value for the total IN yield (Figure S2).

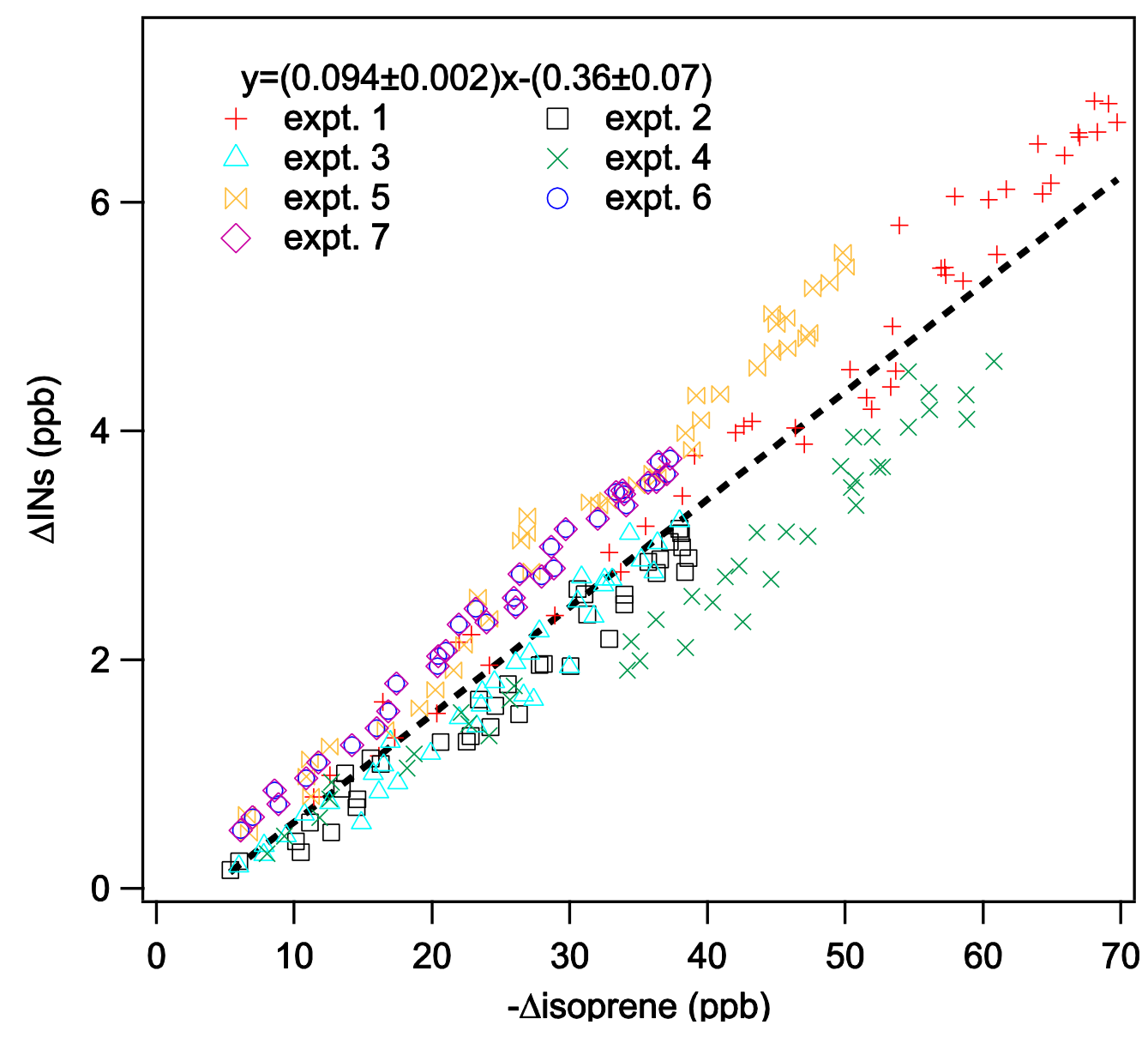

Figure S2. Initial guess value for IN yield, with IN sensitivity calculated based on $\mathrm{RO}_{2}$ isomer distribution. 
The iterative process was started by applying the guess value for IN yield in the MCM-based OD model and simulating the production and loss of IN isomers in the chamber. From the model a time-dependent IN isomer distribution was obtained, which was then used to calculate the new isomer-weighted IN sensitivity and IN yield. The new IN yield was applied in the OD model again, which generated an IN isomer distribution identical to the IN isomer distribution from which this new input IN yield was derived. Figure S3 shows the changing IN sensitivity derived from the OD model.

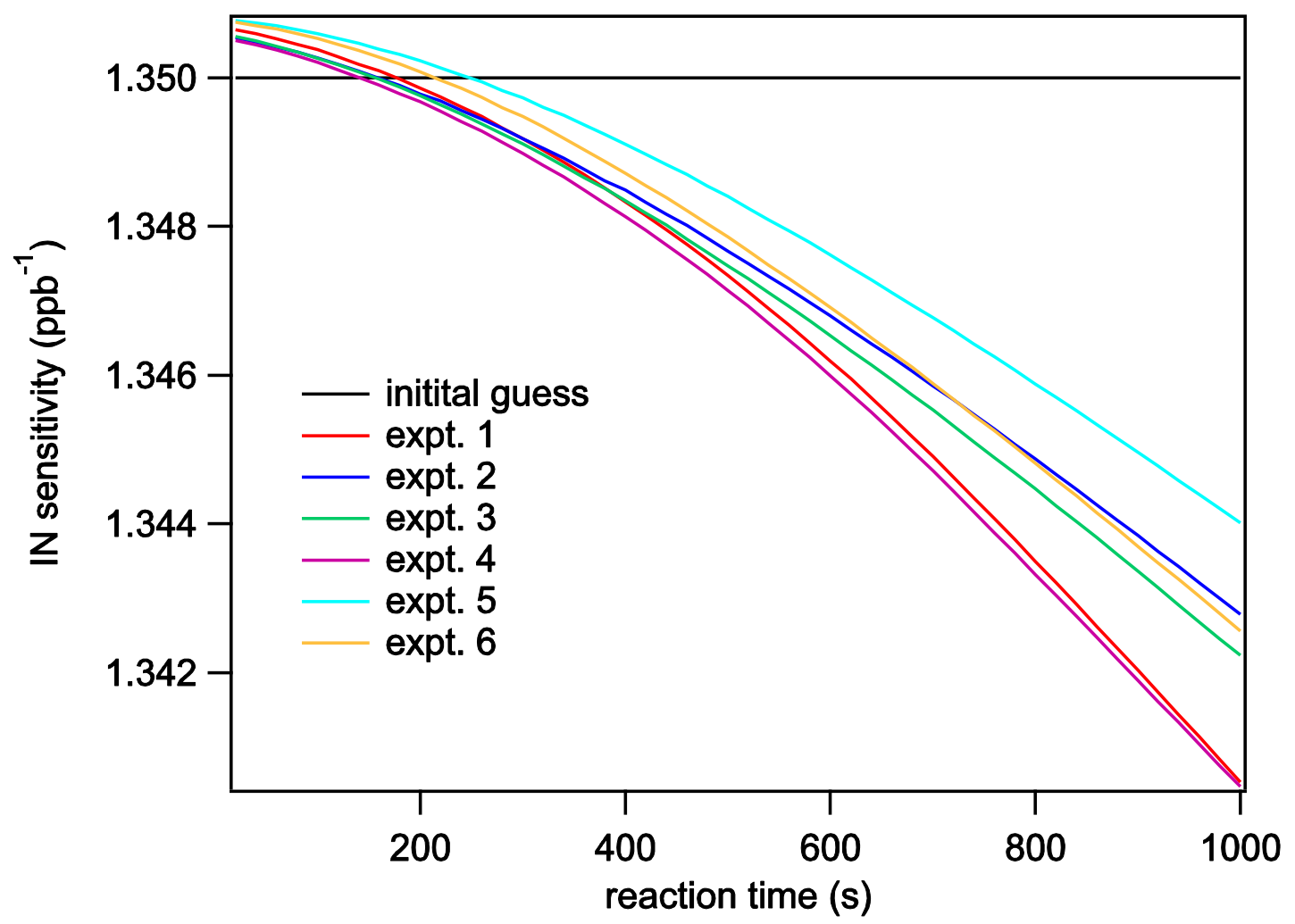

Figure S3. IN sensitivity with reaction time. The constant black line is the initial guess value derived from $\mathrm{RO}_{2}$ isomer distribution. Only the first six experiments are shown, as the duration of the $7^{\text {th }}$ experiment was 3600 s and out of scale.

Figures S4 S7 show the model-observation comparison of isoprene, MVK+MACR, IN and NO for the chamber experiments. The red markers represent measurement data and the black markers represent model results. Each marker shape indicates one experiment. 


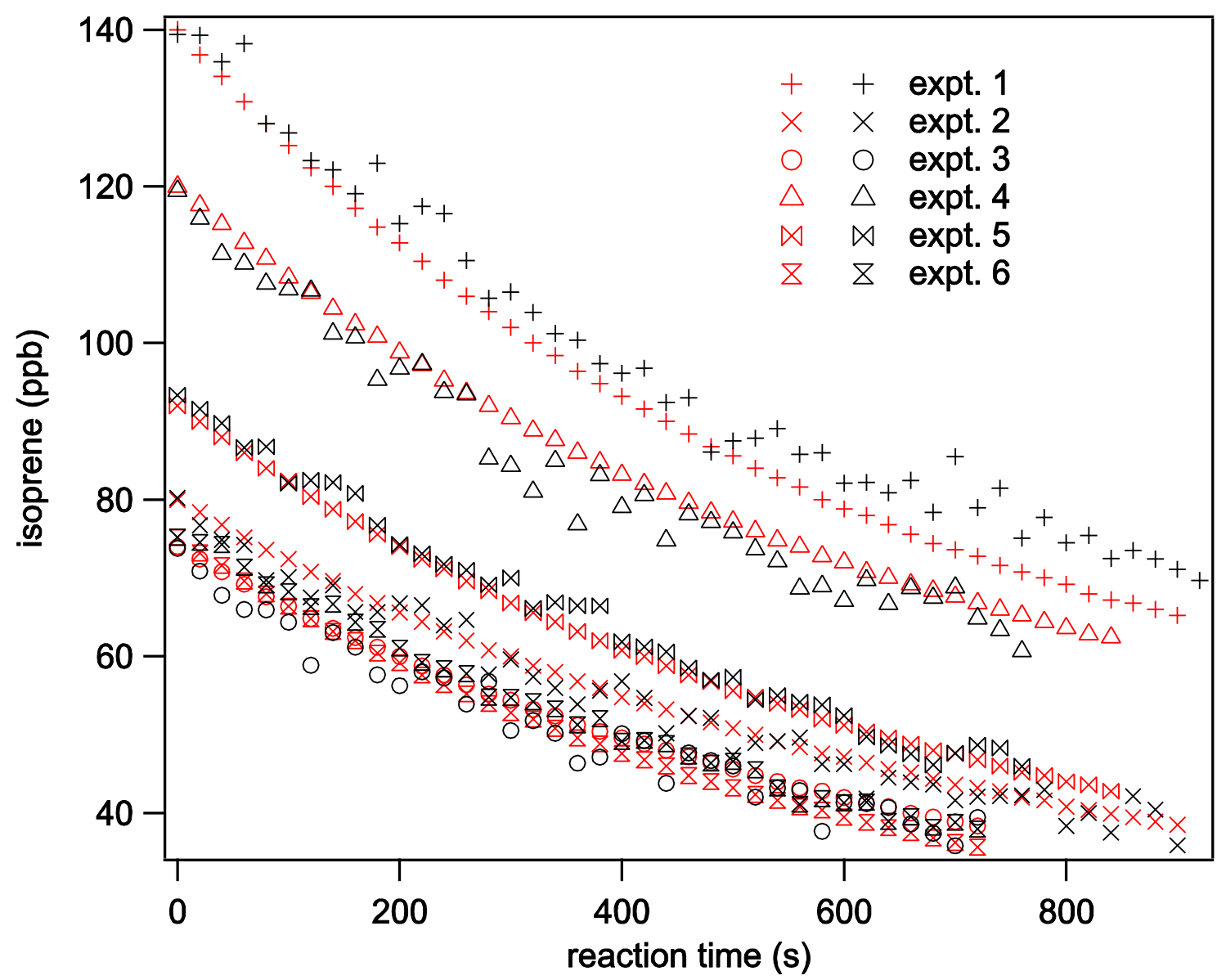

Figure S4. Model and measurement results of isoprene for chamber experiments. The red markers represent measurement data and the black markers represent model results. 


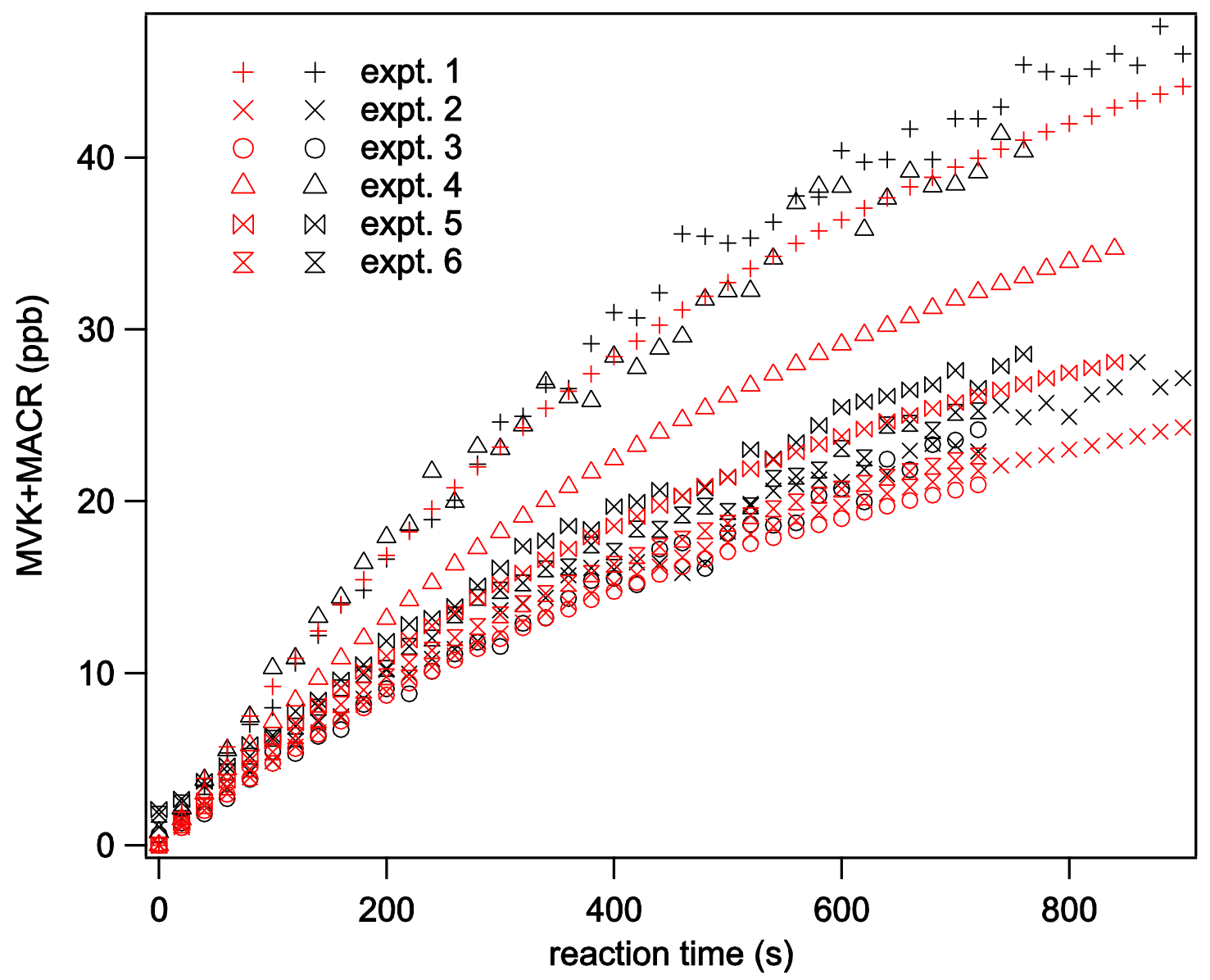

Figure S5. Model and measurement results of the sum of MVK and MACR for chamber experiments. The red markers represent measurement data and the black markers represent model results. 


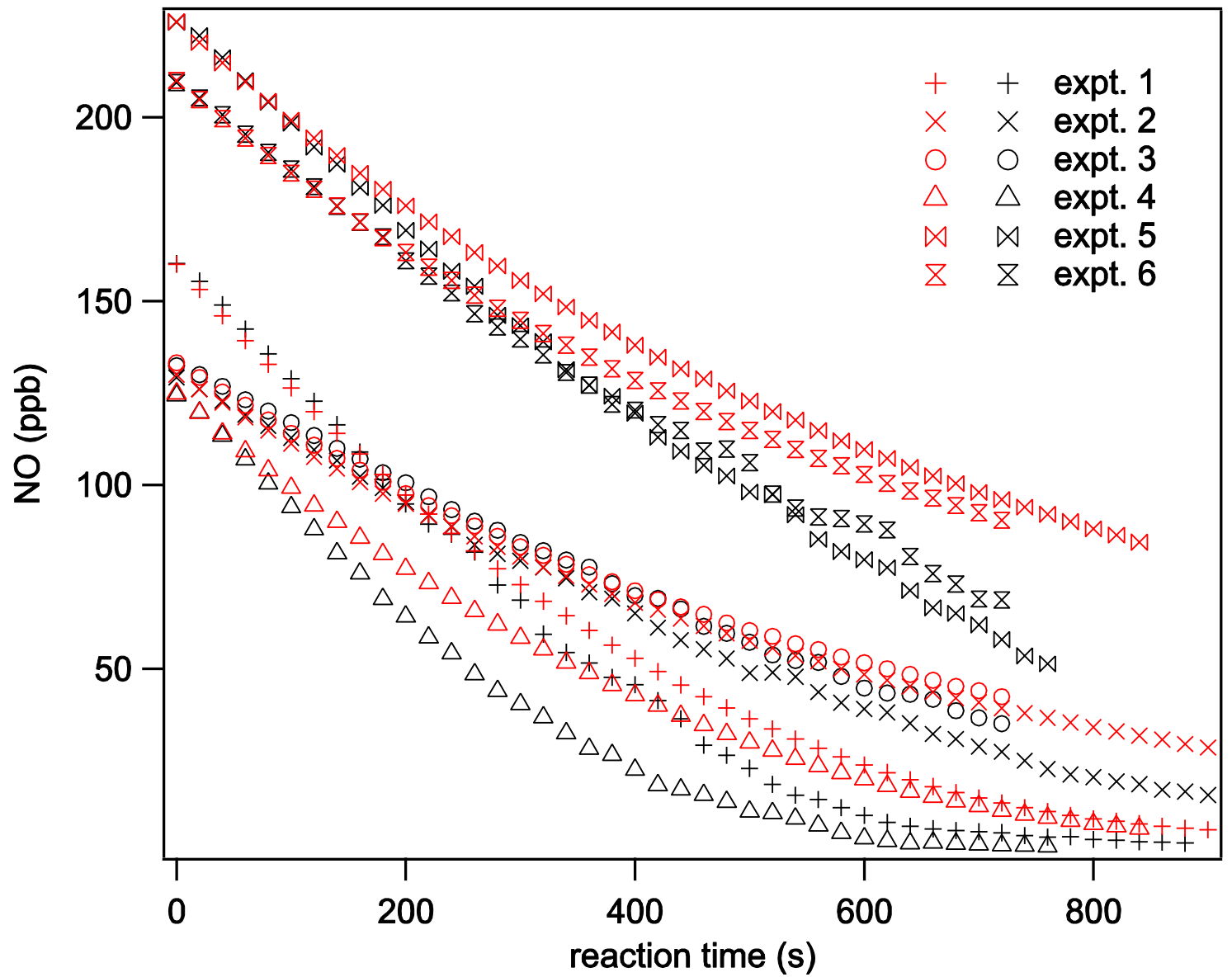

Figure S6. Model and measurement results of NO for chamber experiments. The red markers represent measurement data and the black markers represent model results. Each marker shape indicates one experiment. 


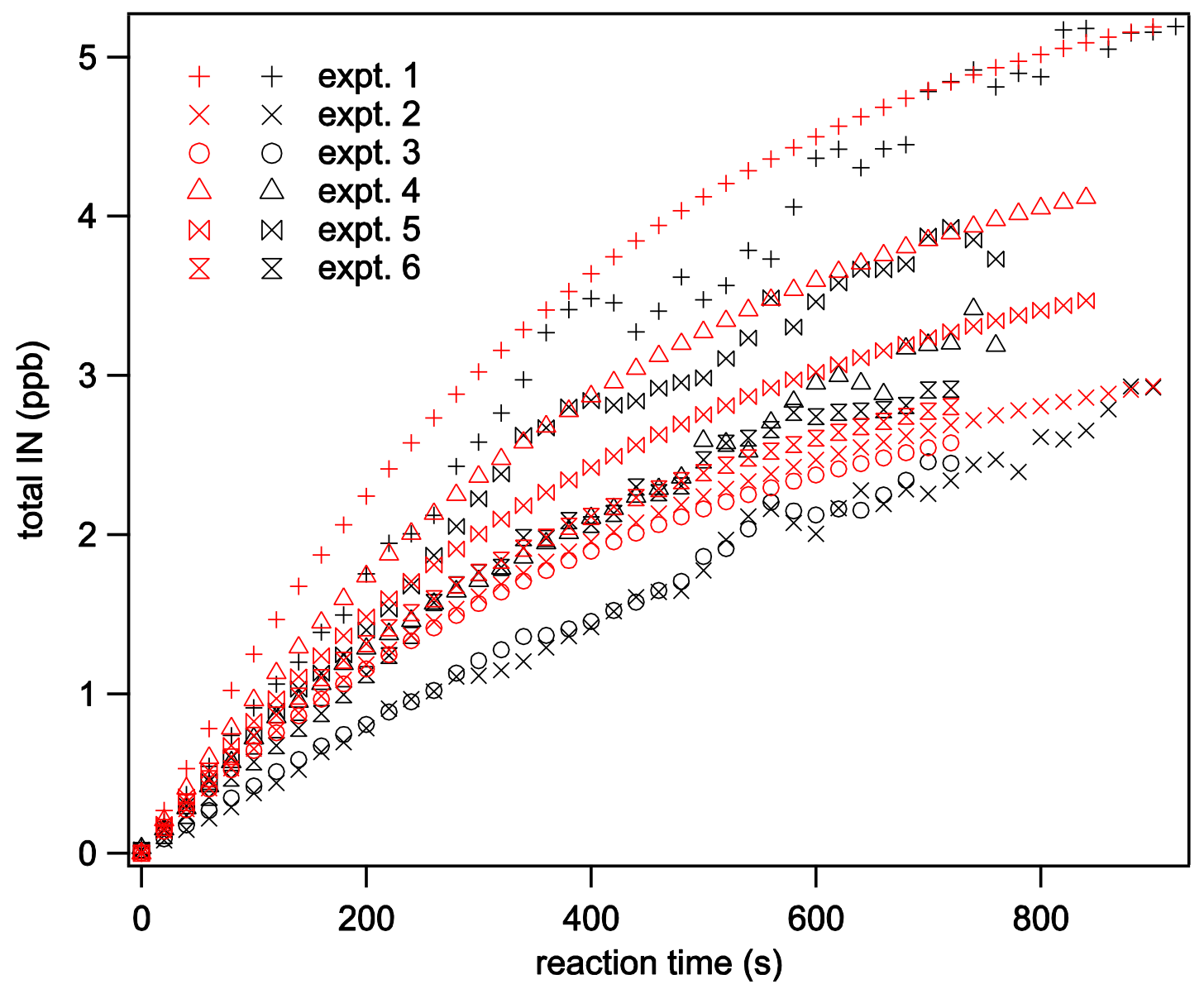

Figure S7. Model and measurement results of total IN for chamber experiments. The red markers represent measurement data and the black markers represent model results.

\subsection{Isomer distribution for IN during SOAS}

The 0D model was used to estimate the relative abundance of IN isomers during the SOAS study. The diurnal average of isoprene, $\mathrm{OH}, \mathrm{NO}, \mathrm{NO}_{2}, \mathrm{O}_{3}$ and $\mathrm{HO}_{2}$ were calculated and the $0 \mathrm{D}$ model was used to simulate the relative concentrations of the IN isomers as they were produced from isoprene oxidation and lost to $\mathrm{OH}, \mathrm{O}_{3}$ and deposition throughout the day. The reaction was initiated at 6:00 $\mathrm{AM}$ (reaction time equals 0 ) and the duration was 24 hours. The simulated IN isomer composition is shown in Figure S8. A diurnal isomer-weighted IN sensitivity was calculated based on the simulated IN isomer distribution (Figure S9). The same diurnal calibration factors were applied to interpret IN raw data for each individual day. 


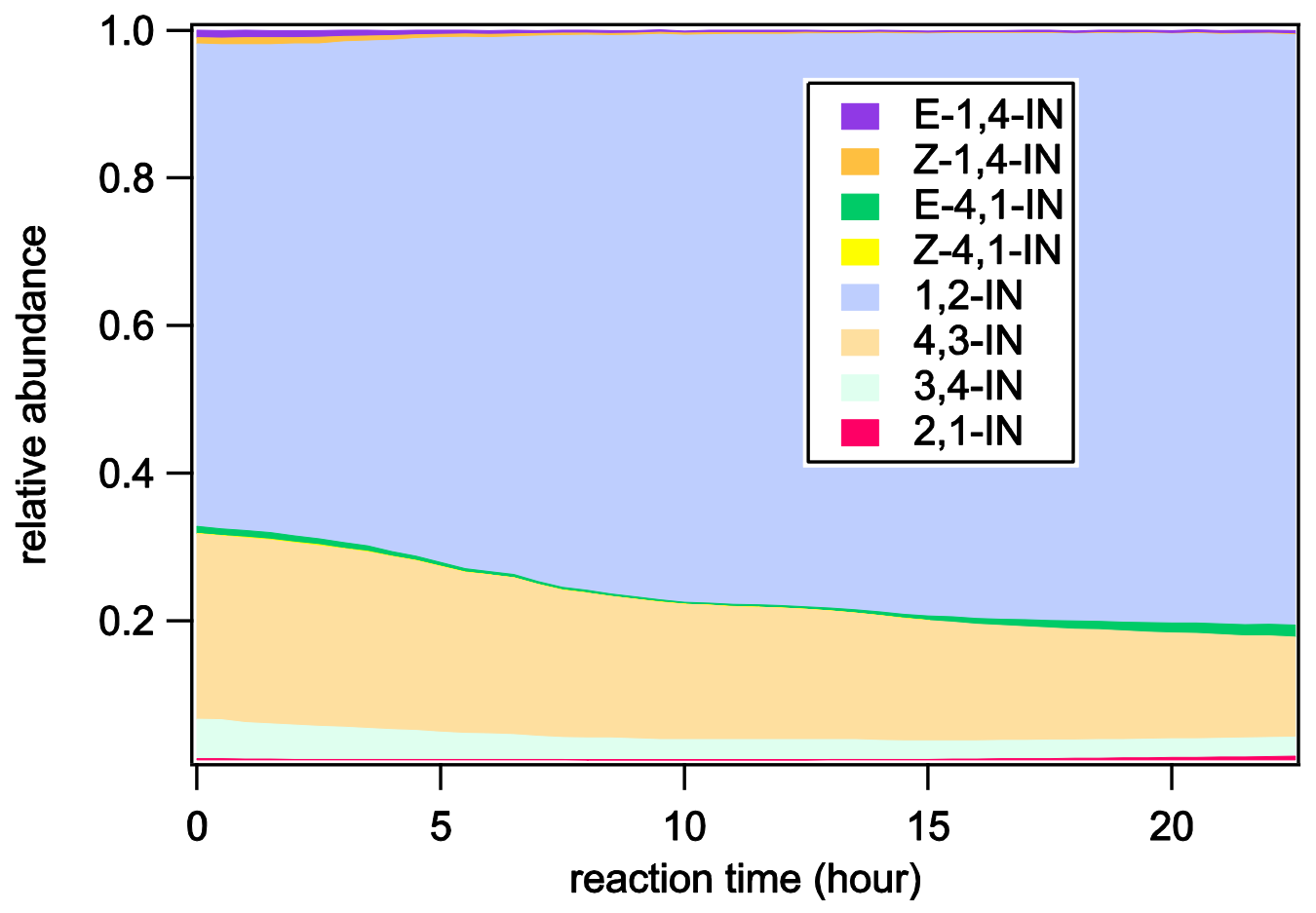

Figure S8. Simulated diurnal IN isomer distribution during SOAS.

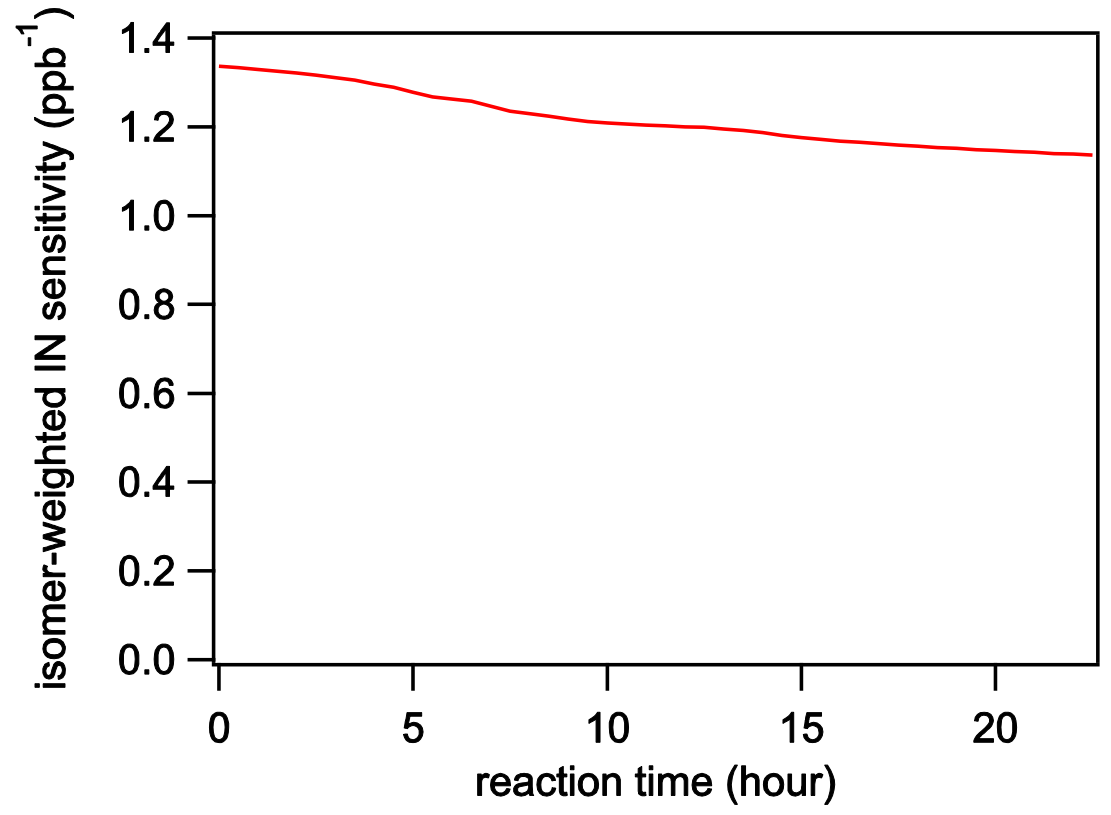

Figure S9. The diurnal isomer-weighted IN sensitivity during SOAS 


\section{Isoprene $\mathrm{RO}_{2}$ distribution and $\mathrm{RO}_{2}$ lifetime}

During SOAS, the $\mathrm{RO}_{2}$ loss rates to $\mathrm{NO}$ and $\mathrm{HO}_{2}$ are slow, compared with 1,6-H shift rate constant for the cis- $\delta-\mathrm{RO}_{2}$. As a result, the yield of total $\mathrm{RO}_{2}$ from $\mathrm{OH}$ addition to isoprene, defined as the amount of $\mathrm{RO}_{2}$ produced relative to the amount of isoprene consumed, can decrease with $\mathrm{RO}_{2}$ lifetime, as $c i s-\delta-\mathrm{RO}_{2}$ radicals isomerize into hydroperoxy aldehyde (HPALD) and other $\mathrm{RO}_{2}$ covert to $c i s-\delta-\mathrm{RO}_{2}$ through $\mathrm{O}_{2}$ loss and addition (Peeters et al., 2014). The yield of the products with respect to $\mathrm{RO}_{2}$ lifetime was calculated with the Kintecus software, and the result is shown in Figure $\mathrm{S} 10$. The $c i s-\delta-\mathrm{RO}_{2}$ radicals become less important with longer $\mathrm{RO}_{2}$ lifetime. Besides $\mathrm{RO}_{2}$ and HPALD, $\mathrm{OH}$ addition to isoprene also forms a stable carbonyl product, with a yield of $2 \%$ (Fan and Zhang, 2004; Peeters et al., 2014). The daytime total $\mathrm{RO}_{2}$ loss rate to $\mathrm{NO}$ and $\mathrm{HO}_{2}$ was on the order of $0.05 \mathrm{~s}^{-1}$, so the $\mathrm{RO}_{2}$ yield at $20 \mathrm{~s}$ was chosen to calculate the IN production rate during SOAS. With an $\mathrm{RO}_{2}$ lifetime of $20 \mathrm{~s}$, the isoprene oxidation products consist of $83 \% \mathrm{RO}_{2}$, $15 \%$ HPALD and $2 \%$ carbonyl product. The $83 \% \mathrm{RO}_{2}$ products include $1 \%$ cis- $\delta-\mathrm{RO}_{2}, 2 \%$ trans$\delta-\mathrm{RO}_{2}$ and $81 \% \beta-\mathrm{RO}_{2}$.

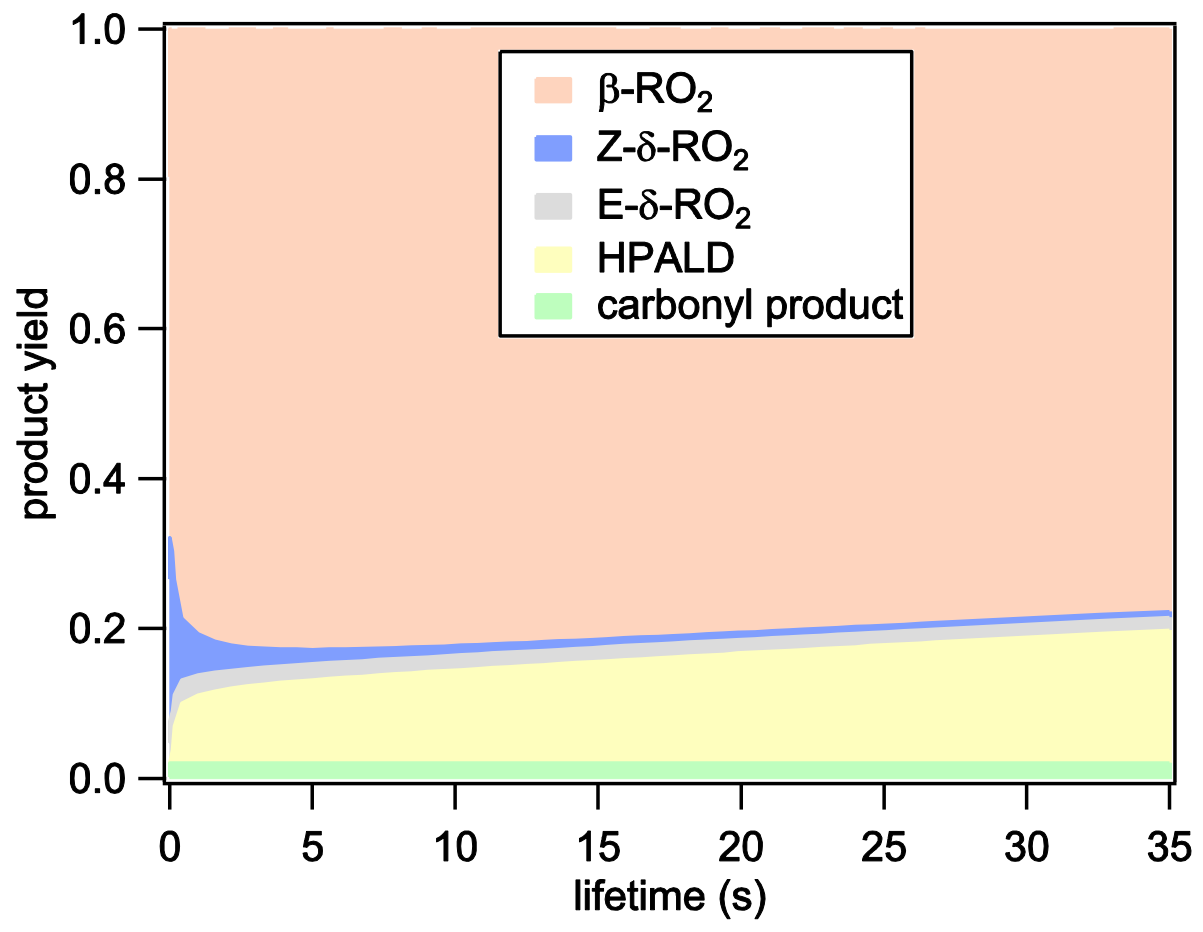

Figure S10. Product yield from $\mathrm{OH}$ addition to isoprene. 


\section{Sensitivity tests on LIM1 mechanism}

The uncertainties in kinetics data for $\mathrm{RO}_{2}$ interconversion and 1,6- $\mathrm{H}$ shift can cause error in the isoprene $\mathrm{RO}_{2}$ and IN isomeric distribution. For the LIM1 mechains, the uncertainties for the equlibrium constants $\mathrm{K}_{\mathrm{eq}}=\mathrm{k}\left(+\mathrm{O}_{2}\right) / \mathrm{k}\left(-\mathrm{O}_{2}\right)$ are a factor of 1.5 , and the uncertainties for the $1,6-\mathrm{H}$ shift rate constants $\mathrm{k}_{1,6-\mathrm{H}}$ are a factor of 2.4 (Peeters et al., 2014). Sensitivity tests were performed by varying the rate constants $\mathrm{k}\left(+\mathrm{O}_{2}\right)$ (or $\mathrm{k}\left(-\mathrm{O}_{2}\right)$ ) by 1.5 times and $\mathrm{k}_{1,6-\mathrm{H}}$ by 2.4 times, and calculating the relative abundance of the $\mathrm{RO}_{2}$ isomers. We found changing $\mathrm{k}_{1,6-\mathrm{H}}$ had no influence on the relative abundance of $\mathrm{RO}_{2}$ isomers, although it significantly influences the yield of HPALD. Changing $\mathrm{k}\left(+\mathrm{O}_{2}\right)$ or $\mathrm{k}\left(-\mathrm{O}_{2}\right)$ only affected the production rate of total $\mathrm{RO}_{2}$, but had no ifluence on the relative abundance of $\mathrm{RO}_{2}$ isomers. The isomeric distribution was affected most when $\mathrm{k}\left(+\mathrm{O}_{2}\right)$ or $\mathrm{k}\left(-\mathrm{O}_{2}\right)$ were varied differently for $\beta-\mathrm{RO}_{2}$ and for $\delta-\mathrm{RO}_{2}$. When $\mathrm{k}\left(+\mathrm{O}_{2}\right)$ values for $\delta-\mathrm{RO}_{2}$ were increased by 1.5 times and $\mathrm{k}\left(-\mathrm{O}_{2}\right)$ values for $\beta-\mathrm{RO}_{2}$ were decreased by 1.5 times, the yield of $1,2-$ $\mathrm{RO}_{2}$ and $4,3-\mathrm{RO}_{2}$ became $32 \%$ and $17 \%$ repectively, which will lead to a total MVK+MACR yield of $49 \%$. This is significantly lower than the experimental MVK+MACR yield from isoprene high NO oxidation (Liu et al., 2013; Park et al., 2004). When $\mathrm{k}\left(+\mathrm{O}_{2}\right)$ values for $\delta-\mathrm{RO}_{2}$ were increased by 1.5 times and $\mathrm{k}\left(-\mathrm{O}_{2}\right)$ values for $\beta-\mathrm{RO}_{2}$ were kept as orignial, the yield of $1,2-\mathrm{RO}_{2}$ and $4,3-\mathrm{RO}_{2}$

were $37 \%$ and $19 \%$, more consistent with the experimental MVK+MACR yield. This set of $\mathrm{RO}_{2}$ isomer distribution was treated as the high $\delta-\mathrm{RO}_{2}$ senario. When $\mathrm{k}\left(+\mathrm{O}_{2}\right)$ values for $\delta-\mathrm{RO}_{2}$ were decreased by 1.5 times and $\mathrm{k}\left(-\mathrm{O}_{2}\right)$ values for $\beta-\mathrm{RO}_{2}$ were increased by 1.5 times, the yield of $1,2-$ $\mathrm{RO}_{2}$ and 4,3- $\mathrm{RO}_{2}$ became $50 \%$ and $26 \%$, and the combined MVK+MACR yield of $76 \%$ was still within the uncertainty reported by experimental studies.This set of $\mathrm{RO}_{2}$ isomer distribution was treated as the high $\beta-\mathrm{RO}_{2}$ scenario. The three set of isomer distributions, base scenario, high $\delta$ $\mathrm{RO}_{2}$ senario and high $\beta-\mathrm{RO}_{2}$ scenario were used to estimate the uncertainty associated with the LIM1 mechanism. The total error in $\mathrm{RO}_{2}$ distribution is $20 \%$, calculated as the weighted relative error of each $\mathrm{RO}_{2}$ isomer. 
Table S2. Deviation of $\mathrm{RO}_{2}$ isomer distrubtion due to error in $\mathrm{RO}_{2}$ interconversion rate constants.

\begin{tabular}{lcccccccc}
\hline $\mathrm{RO}_{2}$ isomer & $\mathrm{Z}-1,4$ & 1,2 & $\mathrm{E}-1,4$ & $\mathrm{Z}-4,1$ & 4,3 & $\mathrm{E}-4,1$ & 3,4 & 2,1 \\
\hline Base & 0.16 & 0.43 & 0.04 & 0.07 & 0.23 & 0.01 & 0.04 & 0.01 \\
high $\delta-\mathrm{RO}_{2}$ & 0.19 & 0.39 & 0.06 & 0.09 & 0.20 & 0.02 & 0.04 & 0.01 \\
high $\beta-\mathrm{RO}_{2}$ & 0.10 & 0.51 & 0.02 & 0.04 & 0.27 & 0.01 & 0.04 & 0.01 \\
\hline
\end{tabular}




\section{$6 \quad$ 4,3-IN sensitivity and sample humidity}

The stability of the CIMS signal for 4,3-IN under different humidity was investigated with the setup in Figure S11a. A gas flow that contained constant 4,3-IN concentration and varying humidity was sampled by the CIMS. The constant 4,3-IN gas flow was generated by bubbling $\mathrm{N}_{2}$ through a 4,3-IN solution kept at $0{ }^{\circ} \mathrm{C}$. The IN signal normalized to the signal of the reagent ion was stable with varying sample humidity (Figure S11b). CIMS was configured with constant water vapor addition to the analyte compounds downstream the orifice.
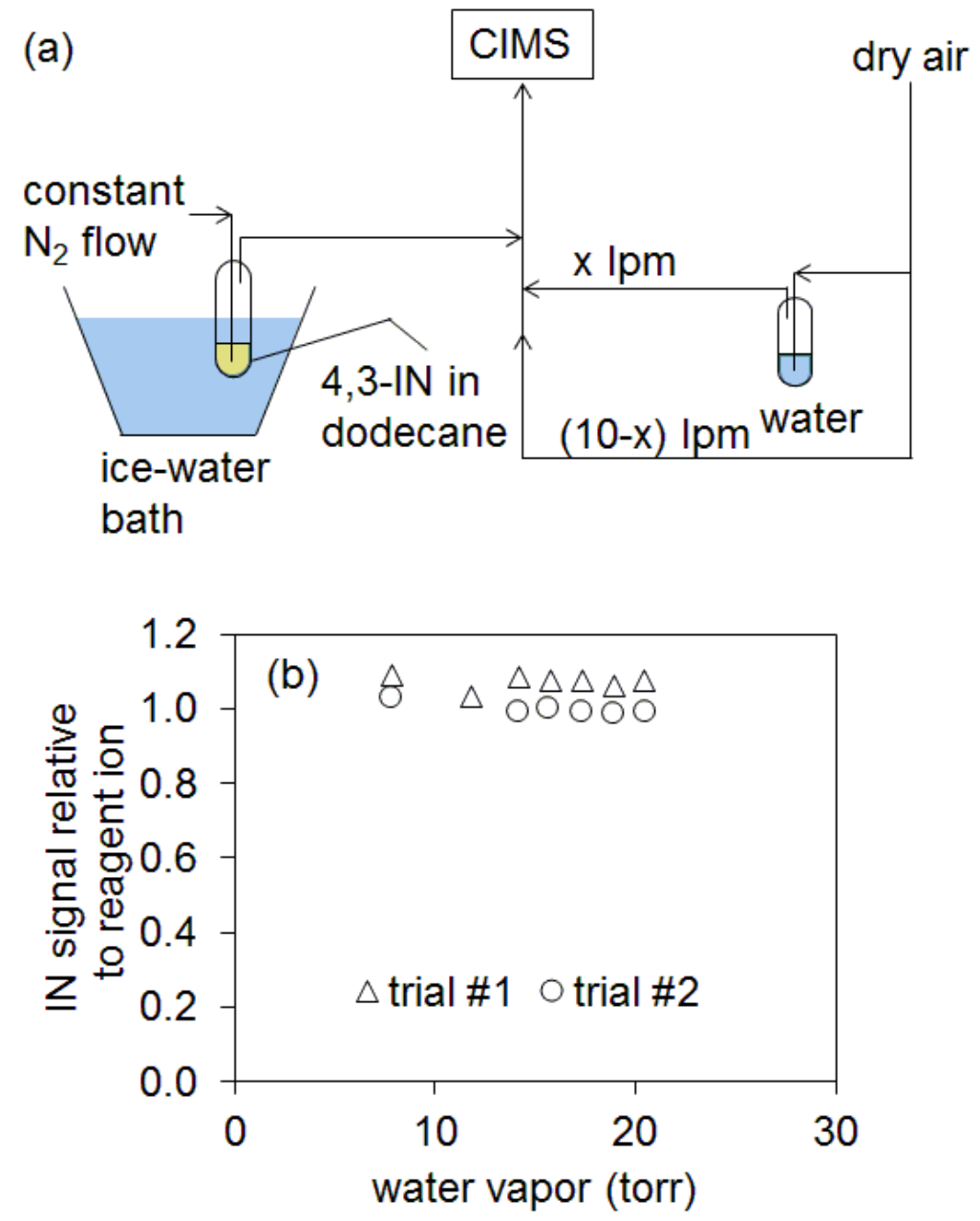

Figure S11. (a) Experimental setup for the CIMS humidity test. (b) Relative CIMS signal for 4,3IN with varying sample humidity. 


\section{The influence of downward mixing on morning [IN] increase}

The rate at which $[\mathrm{IN}] /([\mathrm{MVK}]+[\mathrm{MACR}])$ increased can be described using the following expression.

rate $=\frac{d^{[\mathrm{IN}]} /[\mathrm{MVK}]+[\mathrm{MACR}]}{d t}$

If we define rate as variable $r$, the concentration of IN as $x$ and the concentration of MVK+MACR as $y$, we will have the following expression.

$$
r=\frac{d^{x} / y}{d t}
$$

Since the concentration of IN $(x)$ and the concentration of MVK+MACR $(y)$ both changed with time. Equation (6) can be written as the following.

$r=-\frac{x}{y^{2}} \frac{d y}{d t}+\frac{1}{y} \frac{d x}{d t}$

In Equation (7), $\mathrm{d} y / \mathrm{d} t$ is the growth rate of MVK+MACR, and $\mathrm{d} x / \mathrm{d} t$ is the growth rate of IN.

The 2-hour period from 7:00 AM to 9:00 AM for the 12-day average was chosen as the time window to estimate the contribution of downward mixing. To simplify the calculation, the average changing rate was used for IN and MVK+MACR, instead of the instantanous rate. That modifies Equation (7) to the form of Equation (8) below.

$r=-\frac{\bar{x}}{\bar{y}^{2}} \frac{\Delta y}{\Delta t}+\frac{1}{\bar{y}} \frac{\Delta x}{\Delta t}$

$\bar{x}$ and $\bar{y}$ are the average concentrations of IN and MVK+MACR between 7:00 AM and 9:00 AM. The growth rate of the $[\mathrm{IN}] /([\mathrm{MVK}]+[\mathrm{MACR}])$ ratio was controlled by the growth rate of $\mathrm{MVK}+\mathrm{MACR}$ and the growth rate of IN. The growth rate of the $[\mathrm{IN}] /([\mathrm{MVK}]+[\mathrm{MACR}])$ ratio for measurement data $r_{\text {obs }}$ was higher than the growth rate of the $[\mathrm{IN}] /([\mathrm{MVK}]+[\mathrm{MACR}])$ ratio for simulated results $r_{\text {mod }}$ (Figure $\mathrm{S} 13 \mathrm{a}$ and $\mathrm{S} 13 \mathrm{~b}$ ). The growth rate of [MVK]+[MACR] was less likely to be affected by downward mixing, because significant amount of MVK+MACR was produced at night through isoprene ozonolysis. Therefore here we assume the difference between $r_{\text {obs }}$ and $\mathrm{r}_{\text {mod }}$ was caused only by the difference in $\Delta x / \Delta y$, which is the growth of [IN].

The growth rate of [IN] can be calculated from Equation (9). Using $r_{\text {mod }}$ in Equation (9) we can calculate the the [IN] growth rate caused only by isoprene photochemistry in the current day. 
Using $r_{\text {obs }}$ in Equation (9), we can calculate the total [IN] growth rate, which is the sum of isoprene photochemistry and IN downward mixing. $\bar{x}$ and $\bar{y}$ are average [IN] and [MVK]+[MACR] based on observation. When $r_{\text {obs }}$ is used in Equation (9), $\bar{x}$ based on modeling should be used. However, the OD model cannot simulate absolution IN concentration, so observed average [IN] was used instead, which will make the result slightly biased high.

$\frac{\Delta x}{\Delta t}=\bar{y}\left(r+\frac{\bar{x}}{\bar{y}^{2}} \frac{\Delta y}{\Delta t}\right)$

The calculated total [IN] growth rate with $\mathrm{r}_{\mathrm{obs}}$ is $9.93 \times 10^{-3} \mathrm{ppt} / \mathrm{s}$, which is consistent with the [IN] growth rate derived directly from IN measurement (Figure S13d). When $\mathbf{r}_{\text {mod }}$ was applied in Equation (9), we could calculate [IN] growth caused by isoprene chemistry to be $5.65 \times 10^{-3} \mathrm{ppt} / \mathrm{s}$, $7.28 \times 10^{-3} \mathrm{ppt} / \mathrm{s}$ and $8.98 \times 10^{-3} \mathrm{ppt} / \mathrm{s}$, for IN yield of $6 \%, 9 \%$ and $12 \%$. The difference between total [IN] growth rate and [IN] growth rate caused by photochemistry was attributed to downward mixing. On average, the influence of downward mixing was estimated to be $27( \pm 16) \%$. 

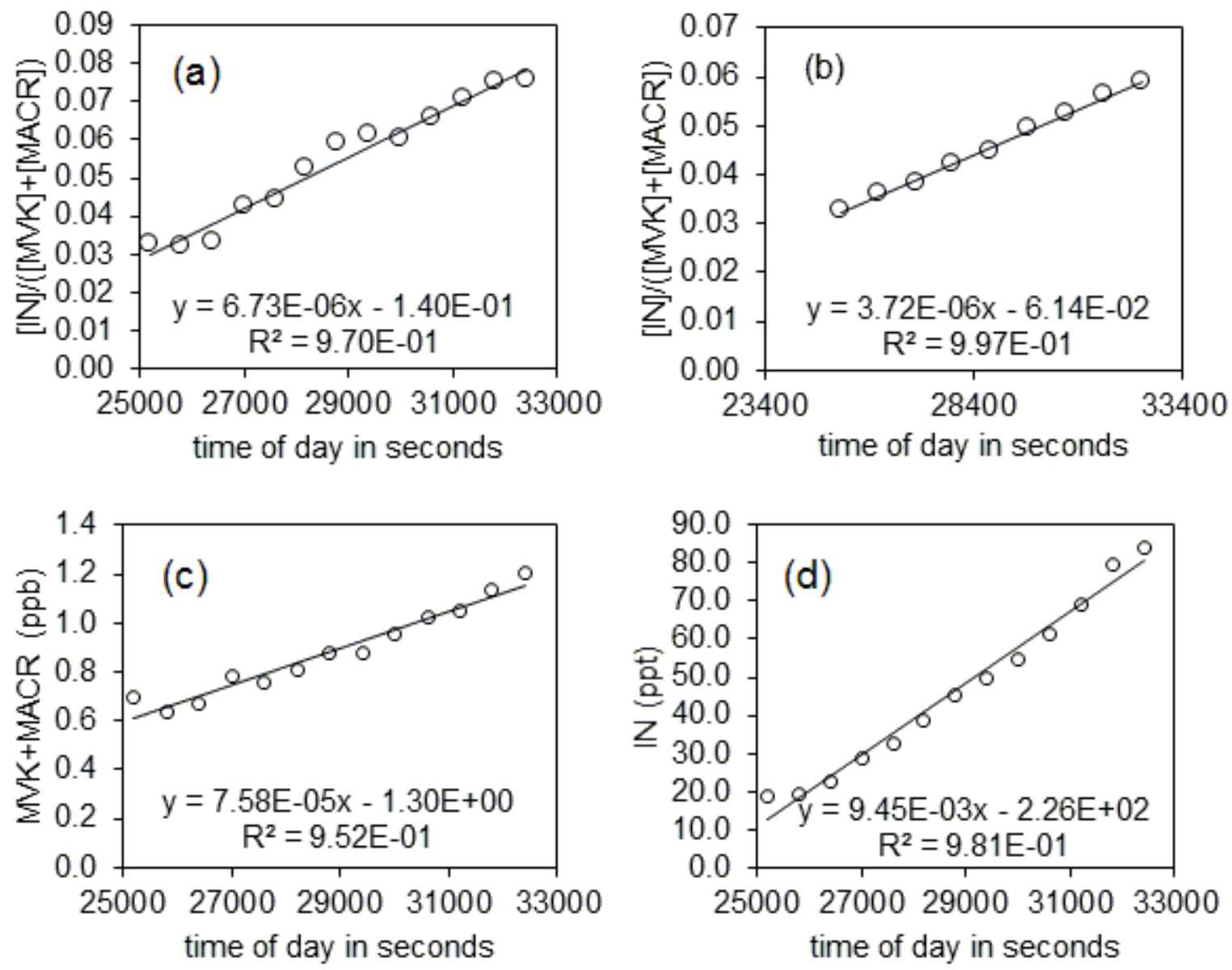

Figure S12. Growth rate of the (a) observed and (b) simulated [IN]/([MVK]+[MACR]) ratio. The simulated ratio is derived with a $9 \%$ IN yield in the model. (c) Growth rate of observed MVK+MACR concentration. (d) Growth rate of observed IN concentration. 


\section{References}

Fan, J., and Zhang, R.: Atmospheric Oxidation Mechanism of Isoprene, Environmental Chemistry, 1, 140, 10.1071/en04045, 2004.

Liu, Y. J., Herdlinger-Blatt, I., McKinney, K. A., and Martin, S. T.: Production of methyl vinyl ketone and methacrolein via the hydroperoxyl pathway of isoprene oxidation, Atmospheric Chemistry and Physics, 13, 5715-5730, 10.5194/acp-13-5715-2013, 2013.

Park, J., Jongsma, C. G., Zhang, R., and North, S. W.: OH/OD Initiated Oxidation of Isoprene in the Presence of O2 and NO, The Journal of Physical Chemistry A, 108, 10688-10697, 10.1021/jp040421t, 2004.

Peeters, J., Müller, J.-F., Stavrakou, T., and Nguyen, V. S.: Hydroxyl Radical Recycling in Isoprene Oxidation Driven by Hydrogen Bonding and Hydrogen Tunneling: The Upgraded LIM1 Mechanism, The Journal of Physical Chemistry A, 118, 8625-8643, 10.1021/jp5033146, 2014. 